\title{
The atrial sound in ischaemic heart disease
}

\author{
Peter P. Turner and John Hunter ${ }^{1}$ \\ From Edgware General Hospital, Edgware, Middlesex
}

A study was made of the diagnostic value of the atrial sound in ischaemic heart disease. It is shown that in ischaemic heart disease, whether or not infarction has occurred, an atrial sound is usually present and can be detected both clinically and phonocardiographically. Its absence makes the presence of ischaemic heart disease unlikely. In a clinical series of 276 consecutive cases of myocardial infarction an atrial sound was heard early in the illness in 98 per cent if the few with dysrhythmias, mitral stenosis, and inaudible heart sounds from impending death are excluded. In a clinical and phonocardiographic study of I 30 consecutive patients admitted to a coronary care unit, highly significant statistical significance is shown for the presence or absence of an atrial sound at the beginning of the illness in diagnosing the presence or absence of myocardial infarction. In 50 consecutive patients with angina and no evidence of infarction all had an atrial sound heard and recorded phonocardiographically. Electrocardiographic evidence of left atrial hypertrophy is common and occurred in 40 per cent of the patients studied. Atrial sounds occur in symptom-free middle-aged and older people and may indicate presymptomatic ischaemic heart disease. This group might repay further study.

The vibrations of atrial contraction, though recordable, are inaudible to the human ear, having too low a frequency as well as too low an amplitude (Crevasse et al., 1960). If frequency and amplitude are accentuated by the atria contracting against closed atrioventricular valves, as may occur in nodal rhythm, in heart block (Ongley et al., r960), and in atrioventricular dissociation, it may become audible.

The atrial sound proper, which is an abnormal ventricular filling sound, occurs later than atrial contraction but before the $Q$ wave of the electrocardiogram. Atrial sounds occurring after the $Q$ wave have been called atrial components of the first sound. In a careful study, Kincaid-Smith and Barlow (1959a) showed that in normal subjects there was an initial lower pitched atrial contribution to the first heart sound. However, unlike the atrial sound and the atrial component of the first heart sound, this did not vary with changes in the PR interval, and it is therefore better called the 'initial first sound vibration'. The atrial sound and the atrial component of the first heart sound can only be separated on their timing with reference to the electrocardiogram, but since in disease states both are audible (Hill et al., 1969) this seems of no clinical value.

The occurrence and behaviour with treatment of

Received 19 October 1972.

1 Present address : Addenbrooke's Hospital, Cambridge. the atrial sound in hypertension has been well documented (Kincaid-Smith and Barlow, 1959b). Atrial sounds in aortic stenosis are also well known, though opinions of their incidence vary; they are almost invariable in hypertrophic obstructive cardiomyopathy. Right-sided atrial sounds occur in pulmonary heart disease and in pulmonary arterial hypertension. They are a particularly useful physical sign in pulmonary embolism. The value of the atrial sound in ischaemic heart disease is less well recognized and it is the purpose of this paper to explore this.

\section{Patients, methods, and results}

r) Clinical series A group of 276 consecutive patients admitted to hospital with myocardial infarction was examined by one of us (P.P.T.) during the years 1966 to 1968. All patients having 'definite acute myocardial infarction' according to the criteria of the World Health Organization (I969) were considered. Those with a diastolic blood pressure of over $90 \mathrm{mmHg}$ were excluded, and those having a further infarct during the period of the study were not included again.

An atrial sound was heard in $244(88.4 \%)$ of these. In most an atrial sound was heard on the first examination but occasionally faint or rapid heart sounds made this impossible, the sound only being detected at a later date. In 32 patients an atrial sound was not heard. This was because of dysrhythmias interfering with atrial activity 
in 16, impaired ventricular filling from mitral stenosis in 2 , loud aortic murmurs making auscultation difficult in $I$, and faint heart sounds from impending death in 8. If these patients are excluded, in only 5 out of 249 patients was an atrial sound not found, giving a revised incidence of 98 per cent. In 3 patients with atrial fibrillation atrial sounds were heard later when sinus rhythm returned.

Of the patients who survived and left hospital, many have been seen again and in none have we observed the atrial sound to disappear. We have seen many patients with a history of a proven myocardial infarction up to as many as 20 years before and with no subsequent symptoms; yet, if they were in sinus rhythm, they have always had an atrial sound.

In $I 10$ patients $(40 \%)$ the $P$ waves in the electrocardiograms were notched and widened to more than $0.12 \mathrm{sec}$, suggesting left atrial hypertrophy.

2) Phonocardiographic series In view of the clinical findings a phonocardiographic study was carried out. Recordings were made on consecutive admissions to a coronary care unit. The recordings were made using a Mingograph 34 (Elema-Schönander) direct writing instrument set at a frequency range corresponding to the low limits of the human ear. Phonocardiographic records were taken simultaneously from the base and from the site where an atrial sound could most easily be heard. Standard lead II of the electrocardiogram was recorded at the same time. If an atrial sound was not recorded, a second attempt was made with the patient turned to the left holding his breath in expiration. Recordings were made as soon as possible after admission, usually within 12 hours, and without the operator having any knowledge of the history or findings other than what was obvious at the bedside.

The recording was made as soon as possible in order to test the diagnostic value of the presence of an atrial sound in the early stages of myocardial infarction, and the phonocardiograms were analysed before the final diagnosis was known.

On the phonocardiogram an atrial sound appears as consistent, low pitched, low amplitude vibrations fol-

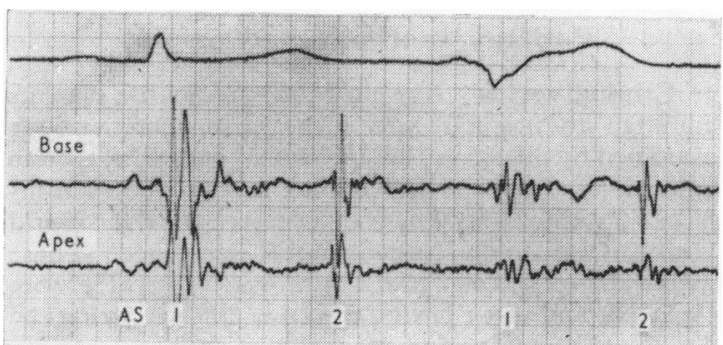

FIG. I Male patient aged 64 years known to have ischaemic heart disease. To show the occurrence of an atrial sound with a normally conducted beat and its absence with a ventricular ectopic beat. (100 $\mathrm{mm} / \mathrm{sec}$, low frequency.)
TABLE Phonocardiographic series of 145 consecutive admissions to coronary care unit

\begin{tabular}{lr}
\hline Group & No. \\
\hline Excluded from study: & \multicolumn{1}{c}{ I5 } \\
Died before phonocardiogram recorded & 5 \\
No infarct - discharged before phonocardio- & 8 \\
gram recorded & \multicolumn{2}{c}{8} \\
Complete heart block - admitted for pacemaker & 29 \\
\hline Acute myocardial infarct: & 7 \\
Excluded (summation gallop) & I \\
Excluded (pericardial rub) & 62 \\
Atrial sound present & 7 \\
Atrial component of first heart sound present & I2 \\
No added sound & 37 \\
No infarct: & I I \\
Atrial sound present & 5 \\
Atrial component of first heart sound present & 2 I \\
No added sound & 4 \\
Diagnosis uncertain & I30 \\
\hline Total patients studied & \\
\hline
\end{tabular}

Statistical significance of the incidence of an atrial sound or an atrial component of the first heart sound in the two groups $\chi^{2}=$ 20.145, $\mathrm{P}<0.001$.

lowing the beginning of the $P$ wave of the simultaneously recorded electrocardiogram but preceding the clearly defined greater amplitude initial vibrations of the first heart sound, whether beginning before or after the $Q$ wave. The clear distinction between the presence or absence of an atrial sound is illustrated in Fig. I, where it is seen in association with the normally conducted beat but not with the following ventricular ectopic beat. These vibrations have been called an atrial sound when beginning before the start of the $Q$ wave and an atrial component of the first heart sound when beginning after it. We believe this to be confusing and of no clinical value, but have analysed this series in this manner in order to show that they both have the same significance.

The phonocardiogram was also used to measure the heart rate, the PR interval, the interval from the start of the P wave to the start of the atrial sound (PG interval), the interval between the atrial sound and the first sound ( $G S_{1}$ interval), and that between the $Q$ wave and the first and second sounds $\left(\mathrm{QS}_{1}\right.$ and $\mathrm{QS}_{2}$ intervals).

Clinical information was obtained from case summaries. These included the patient's age, sex, blood pressure, and the occurrence of arrhythmias. Left ventricular size was assessed from posteroanterior $x$-rays of the chest taken during convalescence. Cardiac failure was judged to have been present if the typical signs of congestion had been observed or if clinical or radiological examination had revealed the presence of pulmonary oedema at any time during the patient's stay in hospital. The final diagnosis of myocardial infarction was based on the usual clinical, electrocardiographic, and biochemical data. It should be noted that in all the patients who had atrial sounds or atrial components of 
first heart sounds recorded they were also heard clinically.

Details of patients studied are given in the Table. Of I30 patients, 89 had had a myocardial infarction. In 7 , a clear presystolic sound was recorded but it fell less than 0.25 sec after the second heart sound and thus could have been a third sound or a summation sound rather than an atrial sound (Weitzman, 1955). In an eighth patient, the phonocardiograph could not be analysed because of a pericardial rub. These patients were excluded from the analysis. Of the remaining 81 patients with infarcts, 62 had atrial sounds, 7 had an atrial component of the first heart sound, and I2 had no presystolic sound.

The group of 37 patients without infarcts included 15 who were known to have previous ischaemic heart disease. Of the 37 , II had an atrial sound, 5 an atrial component of the first heart sound, and $2 \mathrm{I}$ no presystolic sound. The difference in the incidence of an atrial sound or an atrial component of the first heart sound in the two groups is significant $\left(\chi^{2}=20.145, \mathrm{P}<0.00 \mathrm{I}\right)$.

A statistical analysis of clinical features of the patients with an atrial sound or an atrial component of the first heart sound and those without was made. ${ }^{1}$ There was no significant difference in the age, heart rate, or blood pressure of patients with atrial sounds and those without, though the highest level of the serum aspartate aminotransferase (SGOT) recorded in patients with atrial sounds is significantly greater than in those without. The presence of an atrial sound was not related to sex, or to the occurrence of cardiac failure or left ventricular hypertrophy. Atrial arrhythmias, however, significantly reduced the frequency of atrial sounds.

Consideration of the 12 patients with definite infarcts in whom no atrial sound was detected showed that 9 had an atrial arrhythmia at the time of recording. Another had first-degree heart block. No arrhythmia was detected in the other 2 patients. In 31 patients in whom a second phonocardiogram was recorded after convalescence, and in whom an atrial sound was still present,

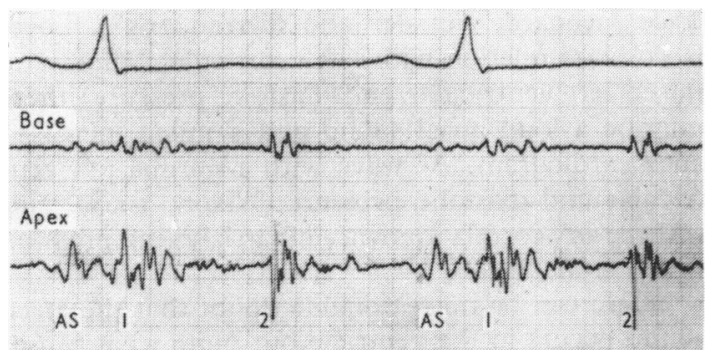

FIG. 2 Atrial sound recorded after first myocardial infarction in a 56-year-old man. (I00 $\mathrm{mm} / \mathrm{sec}$, and low frequency.)

1 Copies of the tables of statistical analysis can be obtained by writing to P. P. Turner. there was no change in the relation of the atrial sound to the first sound, the mean $\mathrm{GS}_{1}$ interval in both sets of recordings being $0.102 \mathrm{sec}$ (Fig. 2 and 3 ).

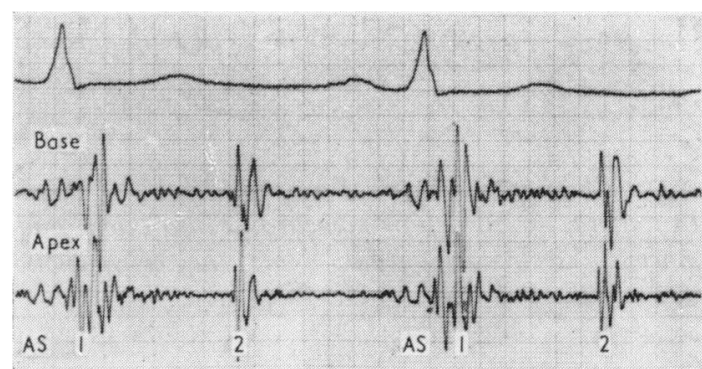

FIG. 3 Same patient as Fig. 2. Atrial sound still present three months after myocardial infarction. Heart rate much the same. The beginning of the sound is a little nearer the $Q R S$ complex than it was before.

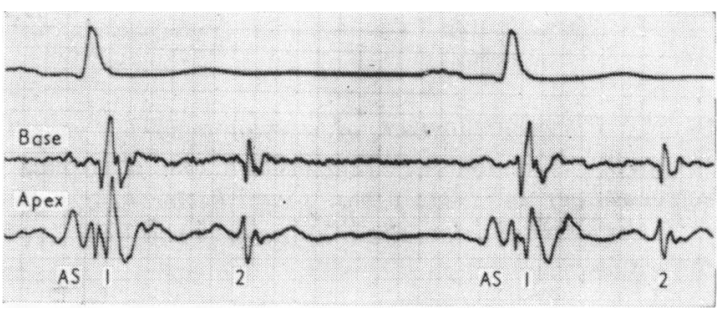

FIG. 4 Phonocardiogram of a man aged 56 years with angina but no history of infarction and a normal electrocardiogram. Note the conspicuous atrial sound. (100 $\mathrm{mm} / \mathrm{sec}$, low frequency.)

3) Angina series We had noted that atrial sounds were not only heard in patients who had had a myocardial infarction but that they were audible in patients with angina, whether or not there was any evidence of infarction having occurred.

In order to record this graphically, a consecutive series of 50 patients attending a cardiac clinic for the first time with a history of angina pectoris was studied clinically and phonocardiographically. Those with a casual diastolic blood pressure of over $90 \mathrm{mmHg}$ were excluded as were those with historical or electrocardiographic evidence of infarction.

In the series of 50 there were 12 women of age range 49 to 68 years and 38 men of age range 39 to 80 years. All were in sinus rhythm and in all an atrial sound was heard. A phonocardiogram was then recorded as previously described. In all 50 cases an atrial sound was present (Fig. 4, 5, and 6). 


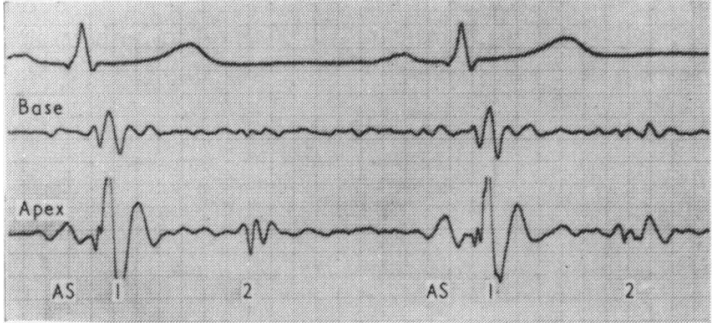

FIG. 5 Phonocardiogram of a woman aged 55 years with angina, no history of myocardial infarction, and a normal electrocardiogram. Note the conspicuous atrial sound. (100 mm/sec, low frequency.)

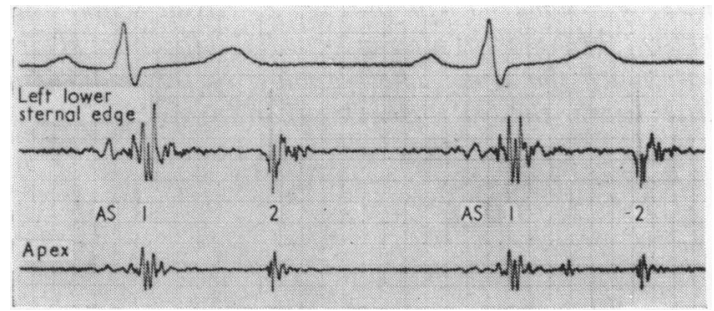

FIG. 6 Phonocardiogram of a man aged 64 years with angina. No history of infarction and a normal electrocardiogram. Note atrial sound better heard at left lower sternal edge than at apex. (100 $\mathrm{mm} / \mathrm{sec}$, low frequency.)

\section{Discussion}

Like so many physical signs, the atrial sound has to be sought with care, but there are no great difficulties so long as the possibility of its existence is kept in mind. The atrial sound of ischaemic heart disease is low pitched and is best heard with the bell of the stethoscope lightly applied to the chest wall. It is usually best heard at the apex and may be very localized. Occasionally it may be better heard at the left sternal edge (Fig. 6). It varies in intensity with respiration showing delayed expiratory augmentation. If not heard readily it should be sought, like a mitral diastolic murmur, by turning the patient on to the left side and listening at the apex, instructing the patient to hold his breath at the end of expiration, listening to the first few beats, for the sound may later disappear as venous return diminishes. Gentle exercise may also help in bringing out the sound.

The atrial sound is not infrequently seen and felt as an atrial beat and very occasionally, because of its low frequency, it may be seen and felt when it cannot be heard.

Wide splitting of the first heart sound is quite common, particularly in young people and may give rise to diagnostic difficulty. However, wide splitting is less common in middle-aged people, the sounds are usually of a higher pitch and, if the heart rate is not too fast, it may be possible to determine that the first element does not precede the carotid impulse, unlike the atrial sound which does.

Atrial activity is necessary for the production of an atrial sound. It is not heard in atrial fibrillation or standstill. With ventricular ectopic beats it is not present (Fig. I) and in patients with atrial sounds on ventricular demand pacing an atrial sound is not heard or recorded with the paced beats.

The mechanism of production of the atrial sound has attracted a great deal of attention. The contraction of the healthy atrium does produce very low intensity, low pitched vibrations that occur 0.07 to $0.14 \mathrm{sec}$ after the beginning of the $P$ wave of the simultaneously recorded electrocardiogram. These vibrations can be seen on the phonocardiogram but are inaudible (Weitzman, 1955; Kincaid-Smith and Barlow, 1959a). Because they are inaudible they are of little interest to the clinician.

The audible atrial sound heard by the clinician is later than mechanical atrial contraction. It occurs 0.09 to $0.16 \mathrm{sec}$ after the $P$ wave if related to the right atrium and 0.12 to $0.24 \mathrm{sec}$ if to the left atrium. It has been shown by intracardiac phonocardiography that the atrial sound is heard in the ventricle and coincides with those recorded by external phonocardiography (Crevasse et al., 1960; Luisada and Shah, 1964).

These audible vibrations follow atrial systole, occur in the ventricle, and are simultaneous with the pressure wave (atrial ' $k i c k$ ') resulting from atrial contraction and appearing in the ventricular pressure trace (Leonard, Weissler, and Warren, 1958). There is no close relation with left ventricular failure and raised left ventricular end-diastolic pressure; there may be a loud atrial sound and a much increased apex cardiogram ' $A$ ' wave with a normal left ventricular end-diastolic pressure (Nixon, 1968). Nor is there any correlation with left atrial mean pressure (Shah et al., 1968).

There can be no reasonable doubt that the atrial sound occurs in the ventricle but quite what causes it is uncertain. Kuo et al. (1957) showed that at the time of the sound atrial pressure was higher than ventricular pressure, so it is unlikely to be due to valve closure. Both inaudible and audible atrial sounds can be recorded in complete heart block and, as ventricular filling increases towards later diastole, the interval between the onset of the $P$ wave and the 
atrial sound vibrations diminishes (Kincaid-Smith and Barlow, 1959b), suggesting that the sound is related to the state of ventricular filling rather than to valve movement.

It is probable that the atrial sound is a ventricular filling sound brought about by the need for more forceful atrial activity. The diseased ventricle with decreased compliance, increased resistance to filling, and decreased early systolic filling demands a larger atrial contribution (Shah et al., 1968). This does not necessarily, and indeed does not usually, imply impaired ventricular function.

The atrial sound used to be considered a dire prognostic sign (Holt, I927; White, I928; Duchosal, 1932; Bramwell, 1935; Lian, 1948). More recently it has been recognized that in hypertension it may occur without any evidence of left ventricular failure and without any symptoms being present (Miles, 1951; Weitzman, 1955; Evans, 1957). We have shown that an audible atrial sound may still be heard very many years after the onset of ischaemic heart disease, the patient having led a normal life; its presence does not necessarily prognosticate early demise or even early invalidism. We believe that audible atrial sounds are not heard in normal hearts and this view is shared by others (Weitzman, 1955; Kincaid-Smith and Barlow, 1959a; Leatham, 1970). Though it seems likely that the earlier the occurrence of the atrial sound the worse the state of the ventricle and the worse the prognosis (KincaidSmith and Barlow, I959a), our findings suggest that it is of most value as a diagnostic sign. Provided that sinus rhythm is present and the heart sounds easily heard, the absence of an atrial sound makes the diagnosis of ischaemic heart disease most unlikely.

The reported incidence of atrial sounds in ischaemic heart disease has varied enormously. Even recently some writers have found the incidence quite low. McDonald (1968) in roo consecutive outpatients with ischaemic heart disease found atrial sounds in only 13, far fewer than had third heart sounds or paradoxical splitting of the second sound. In I50 patients with myocardial infarction admitted to a coronary care unit, only 3 I per cent had atrial sounds (McDonald, I968). In I2 patients with ischaemic heart disease shown to have reversed splitting of the second sound, only I was observed to have an atrial sound on independent physical examinations by 2 physicians (Agnew et al., 1967). Stock (1966) found a 50 per cent incidence after myocardial infarction. Meltzer (1968) used continuous phonocardiography in patients after myocardial infarction and found that more than 60 per cent had transient third and fourth heart sounds.

However, Master and Friedman (1942) found an 83 per cent incidence, though they believed only 33 per cent were significant on the grounds of amplitude and frequency. More recently it has been recognized that the incidence after myocardial infarction is much higher than those quoted. Harvey (1969) states that the absence of even a faint atrial gallop is unusual in a patient who has had a previous myocardial infarction, and Hill et al. (1969) studied 50 consecutive patients admitted to a coronary care unit with serial phonocardiograms: 20 of these had proven myocardial infarction and all had atrial gallops; in 7 the atrial sound moved towards the first sound to become an atrial component of the first sound but remained audible, no further movement occurring after 4 weeks; these changes were not related to changes in the PR interval. Of the 50, 18 had ischaemic heart disease but no evidence of infarction; all had atrial sounds or atrial components. The other 12 had no evidence of atrial sounds. A further 87 patients with myocardial infarction were studied less closely and of these 85 had atrial gallops; of the other 2, one had mitral stenosis and the other left atrial fibrosis at necropsy.

Our findings are in accord with this study except that we did not find any migration of atrial sounds towards the first sound in those studied serially. Our study, however, goes further. We have been able to show that, provided the patient is in sinus rhythm and heart sounds can be heard, an audible atrial sound is present and can be recorded if the patient has ischaemic heart disease of any kind. If the patient has had a myocardial infarction, no matter how long before, an atrial sound can be heard. If the patient has angina without evidence of ever having had a myocardial infarction, an atrial sound will still be heard.

It is of some interest that in our study, using strict criteria, there is electrocardiographic evidence of left atrial hypertrophy in 40 per cent of our patients, lending support to the view that left atrial work is increased and that the necessary hyper-

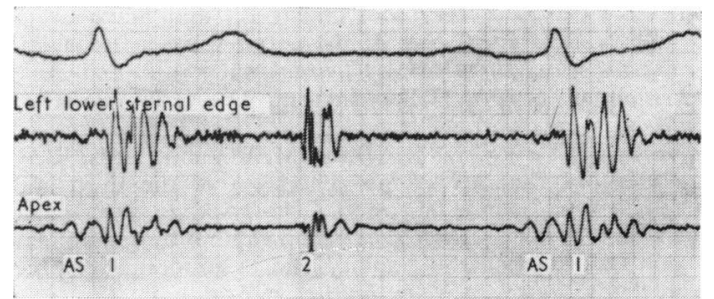

FIG. 7 Phonocardiogram of a man aged $5 I$ years, with no history of angina or myocardial infarction, $a$ normal electrocardiogram, blood pressure 140/85 $\mathrm{mmHg}$, yet a clearly audible and recorded atrial sound. (I0o $\mathrm{mm} / \mathrm{sec}$, low frequency.) 
trophy has occurred. This is contrary to the finding of Wood and Selzer (1939), who found wide, bifid, or flat-topped, low-voltage $P$ waves in left ventricular failure from hypertension, and related to its severity, but none in 25 patients with ischaemic heart disease and presumably without left ventricular failure. A recent study (Heikkilä and Luomanmäki, 1970) has shown serial $P$ wave changes reflecting the degree of left ventricular failure after myocardial infarction.

In the several years we have been doing this work we have become increasingly aware of a group of middle-aged and older people in whom an atrial sound can be heard and recorded when there is neither historical nor electrocardiographic evidence of ischaemic heart disease (Fig. 7). This is observed more often in men than in women. Subsequently we have several times seen these patients when they have developed angina or frank myocardial infarction. We have made no formal study of this group as yet, but we believe that this stigma indicates an early presymptomatic form of ischaemic heart disease. We believe that the atrial sound is a very sensitive indicator of decreased left ventricular compliance and is present when myocardial perfusion is reduced and compliance impaired, and yet not so reduced or impaired as to produce symptoms. We believe that this group deserves further study.

We would like to thank Dr. D. G. C. Davidson, Dr. Margaret Rose, and Dr. Sandra King for their considerable contributions to the work on which this paper is based, our colleagues at Edgware General Hospital for permission to study patients admitted under their care to the coronary care unit, and Dr. R. P. Knill-Jones for his help with the statistical analyses. We should also like to record our indebtedness to the North West Metropolitan Regional Hospital Board Research Committee for their generous grant, without which this study could not have been carried out.

\section{References}

Agnew, T., Bucher, H., McDonald, L., and Seymour, J. (1967). Delayed closure of the aortic valve in ischaemic heart disease. British Heart fournal, 29, 775.

Bramwell, C. (1935). Gallop rhythm. Quarterly fournal of Medicine, n.s. 4, 149.

Crevasse, L., Taylor, W. J., Wheat, M. W., and Leeds, R. F. (1960). Mechanism of the generation of the third and fourth heart sounds (abstract). Circulation, 22, 737.

Duchosal, P. $(1,32)$. A study of gallop rhythm by a combination of phonocardiographic and electrocardiographic methods. American Heart fournal, 7, 613.

Evans, W. (1957). Hypertonia or uneventful high blood pressure. Lancet, $2,53$.

Harvey, W. P. (1969). Some pertinent physical findings in the clinical evaluation of acute myocardial infarction. Circulation, 39 and 40, Suppl. 4, I75.
Heikkilä, J., and Luomanmäki, K. (I970). Value of serial P wave changes in indicating left heart failure in myocardial infarction. British Heart fournal, 32, 5 IO.

Hill, J. C., O'Rourke, R. A., Lewis, R. P., and McGranahan, G. M. (1969). The diagnostic value of the atrial gallop in acute myocardial infarction. American Heart fournal, 78, 194.

Holt, E. (1927). Gallop rhythm. American Heart Fournal, 2, 453.

Kincaid-Smith, P., and Barlow, J. (I959a). The atrial sound and the atrial component of the first heart sound. British Heart fournal, $21,470$.

Kincaid-Smith, P., and Barlow, J. (I959b). The atrial sound in hypertension and ischaemic heart disease with reference to its timing and mode of production. British Heart fournal, 21, 479.

Kuo, P. T., Schnabel, T. G., Jr., Blakemore, W. S., and Whereat, A. F. (1957). Diastolic gallop sounds, the mechanism of production. Fournal of Clinical Investigation, 36, 1035 .

Leatham, A. (1970). Auscultation of the Heart and Phonocardiography, p. 98. Churchill, London.

Leonard, J. J., Weissler, A. M., and Warren, J. V. (1958). Observations on the mechanism of atrial gallop rhythm. Circulation, 17, 1007.

Lian, C. (1948). The use of the phonocardiograph in clinical cardiology. British Heart fournal, 10, 92.

Luisada, A. A., and Shah, P. M. (1964). Controversial and changing aspects of auscultation. III. Diastolic sounds. American fournal of Cardiology, 13, 243.

McDonald, L. (1968). Diuretic therapy. In Acute Myocardial Infarction, p. 179. Ed. by D. G. Julian and M. F. Oliver. Livingstone, Edinburgh and London.

Master, A. M., and Friedman, R. (1942). A phonocardiographic study of the heart sounds in acute coronary occlusion. American Heart fournal, 24, 196.

Meltzer, L. E. (1968). Early detection of 'pump' failure. In Acute Myocardial Infarction, p. 208. Ed. by D. G. Julian and $M$. F. Oliver, Livingstone, Edinburgh and London.

Miles, B. E. (195I). The clinical significance of gallop rhythm in hypertension. British Heart fournal, 13, 327.

Nixon, P. G. F. (1968). In discussion on early detection of 'pump' failure. In Acute Myocardial Infarction, p. 215. Ed. by D. G. Julian and M. F. Oliver. Livingstone, Edinburgh and London.

Ongley, P. A., Sprague, H. B., Rappaport, M. B., and Nadas, A. S. (1960). Heart Sounds and Murmurs, p. 136. Grune and Stratton, New York and London.

Shah, P. M., Gramiak, R., Kramer, D. H., and Yu, P. N. (1968). Determinants of atrial $\left(S_{4}\right)$ and ventricular $\left(S_{3}\right)$ gallop sounds in primary myocardial disease. New England fournal of Medicine, 278, 753.

Stock, E. (1966). Auscultation and phonocardiography in acute myocardial infarction. Medical fournal of Australia, I, 1060 .

Weitzman, D. (1955). The mechanism and significance of the auricular sound. British Heart fournal, 17, 70.

White, P. D. (1928). The clinical significance of gallop rhythm. Archives of Internal Medicine, 4I, I.

Wood, P., and Selzer, A. (1939). A new sign of left ventricular failure. British Heart fournal, 1, 81.

World Health Organization (1969). Working Group on Ischaemic Heart Disease Registers Part II, p. 22 and Annex II. World Health Organization, Copenhagen.

Requests for reprints to Dr. Peter P. Turner, Edgware General Hospital, Edgware, Middlesex HA8 OAD. 